\title{
APAKAH SIFAT EXTRAVERSION DAN NEUROTICISM BERPENGARUH TERHADAP WHISTLEBLOWING? PENGUJIAN KOMITMEN SEBAGAI PEMEDIASI
}

\author{
Angeli Gavriel Tjahyadi ${ }^{1}$, Andi Ina Yustina ${ }^{2 *}$ \\ 1,2Universitas Presiden, Cikarang - Indonesia \\ ${ }^{1}$ Email: angeligavriel96@gmail.com \\ $2^{*}$ Corresponding Author: a.inayustina@gmail.com
}

KETERANGAN ARTIKEL

Riwayat Artikel

Diterima: 15 Mei 2019

Direvisi: 1 Juni 2019

Disetujui: 15 Juni 2019

Klasifikasi JEL:

M24, K42

Keywords: extraversion, neuroticism, whistleblowing, affective commitment

Kata Kunci: extraversion, neuroticism, whistleblowing, komitmen afektif

\section{ABSTRACT}

This research examines the effect of affective commitment as a mediation variable between the relationship of personality trait (extraversion and neuroticism) to whistleblowing. Data collection used web-based questionnaires and has collected 95 of respondents from individuals who work in the accountant's environment in the service, trade, and manufacturing industry in Indonesia. The researcher tested the hypotheses by using a Structural Equation Modeling (SEM) with Partial Least Squares (PLS). Three of five hypotheses in this research are supported. The result of this research shows both personality trait, extraversion and neuroticism, affect to whistleblowing, and affective commitment not mediates the relationship between extraversion and neuroticism to whistleblowing.

\section{ABSTRAK}

Penelitian ini menguji pengaruh komitmen afektif sebagai variabel mediasi antara hubungan personality trait (extraversion dan neuroticism) terhadap whistleblowing. Pengumpulan data menggunakan kuesioner berbasis web dan telah diperoleh 95 responden dari seluruh individu yang bekerja di lingkungan akuntan, di industri jasa, dagang, dan manufaktur di Indonesia. Peneliti menguji hipotesis dengan menggunakan Structural Equation Modeling (SEM) with Partial Least Squares (PLS). Tiga dari lima hipotesis dalam penelitian ini terdukung. Hasil penelitian menunjukan bahwa kedua sifat personal, yaitu extraversion dan neuroticism, mempengaruhi whistleblowing, dan komitmen afektif tidak memediasi hubungan antara extraversion dan neuroticism terhadap whistleblowing.

\section{PENDAHULUAN}

Persitiwa skandal keuangan dan perilaku disfungsional dalam organisasi seperti dalam peristiwa Worldcom, menyingkapkan bagaimana akuntan dan auditor eksternal turut terlibat dan bertanggung jawab atas terjadinya perilaku disfungsional. Kecurangan yang dilakukan Worldcom tidak terdeteksi oleh Kantor Akuntan Publik Arthur Andersen sebagai auditor eksternal independen. Kasus Worldcom adalah salah satu contoh dari sekian banyaknya kasus kecurangan pelaporan laporan keuangan, dari kasus tersebut kita dapat memahami pentingnya peran whistleblower untuk menyelidiki dan mengeskpos hal-hal yang ilegal ketika manajemen memiliki kekuatan untuk menyembunyikan kecurangan dan auditor 
eksternal tidak lagi dapat dipercaya, atau ketika kecurangan tersebut sulit untuk dideteksi (Cintya \& Yustina, 2019).

Ketika terjadi skandal keuangan, akuntan seringkali menjadi pihak yang mengetahui dengan jelas perilaku disfungsional apa saja yang terjadi dalam perusahaan, karena itu akuntan seringkali mengalami dilema, apakah akan melakukan tindakan whistleblowing dengan cara melaporkan perilaku disfungsional tersebut pada rekan, atasan, atau pihak yang dapat mengatasi masalah tersebut (Liyanarachi \& Alder, 2011).

Whistleblowing adalah perilaku yang tidak hanya terdiri dari niat, namun juga tindakan yang dilakukan individu saat mereka berhadapan dengan pelanggaran di sebuah organisasi (Bjorkelo et al., 2010) dengan cara menyingkapkan kegiatan ilegal di bawah kendali perusahaan kepada pihak yang mungkin dapat melakukan tindakan (Alleyne, 2016). Whistleblowing dapat mempengaruhi kinerja perusahaan, mencegah risiko hilangnya kepercayaan publik dan risiko rusaknya reputasi perusahaan, serta mencegah masalah keuangan (Bjørkelo et al., 2010). Saat mengetahui adanya tindakan ilegal, masingmasing individu memiliki kecenderungan yang berbeda dalam melakukan whistleblowing, ada individu yang menganggap whistleblowing merupakan hal yang perlu dilakukan dan ia akan melakukan tindakan tersebut, ada juga yang tidak melakukan tindakan whistleblowing meskipun ia tahu whistleblowing diperlukan. Menurut penelitian sebelumnya, perbedaan kecenderungan melakukan whistleblowing dapat dipengaruhi oleh faktor kepribadian (Bjorkelo et al., 2010).

Kepribadian/karakter diasumsikan sebagai hal yang mempengaruhi seseorang untuk terlibat atau melakukan perilaku whistleblowing (Bjorkelo et al., 2010). Penelitian sebelumnya (Guenole \& Chernyshenko, 2005; Golberg, 1993) menggunakan Big Five Personality Traits/Five Factor Model (FFM) sebagai acuan dalam membahas perbedaan karakter. Hal ini karena
Big Five ditemukan sebagai fondasi yang kuat dan dapat diterima dalam pembahasan perbedaan karakter di banyak penelitian lintas budaya, bahasa, dan gender. Big Five Personality Traits terdiri dari extraversion, agreeableness, conscientiousness, neuroticism, dan openness. Dalam penelitian ini hanya menggunakan dua dari lima variabel Big Five Personality Traits, variabel yang digunakan adalah extraversion dan neuroticism. Menurut Rusting \& Larsen (1997), dari semua personality traits, extraversion dan neuroticism sudah sangat mewakili kepribadian yang positif dan kepribadian yang negatif. Extraversion berkaitan dengan suasana hati yang menyenangkan dan kepribadian yang positif, sedangkan neuroticism sebaliknya (Judge et al., 2002). Selain perbedaan kepribadian, komitmen organisasi juga menjadi hal yang mempengaruhi seseorang dalam melakukan whistleblowing.

Komitmen organisasi adalah keterlibatan seseorang di organisasi tertentu. Komitmen organisasi bercirikan memiliki kepercayaan dan penerimaan yang kuat terhadap nilai-nilai organisasi, memberikan banyak usaha demi kemajuan perusahaan, dan memiliki keinginan kuat untuk menjadi bagian dari anggota organisasi (Mowday et al., 1979). Menurut Near \& Miceli (1985) individu dengan komitmen organisasi yang tinggi memiliki keinginan untuk melakukan whistleblowing, namun hanya secara internal karena tidak ingin merugikan perusahaan. Penelitian Near \& Miceli (1985) tersebut diperluas oleh Yustina \& Cintya (2019) dengan menghubungkan komitmen organisasi bukan hanya pada keinginan, namun juga pada aksi, individu dengan komitmen organisasi melakukan tindakan whistleblowing hanya secara internal. Sedangkan suatu tindakan dikatakan tindakan whistleblowing jika dilakukan pelaporan baik secara internal ataupun eksternal jika dibutuhkan, dengan tujuan mengatasi tindakan disfungsional di organisasi (Park and Blekinsopp, 2009; Dworkin \& Baucus, 1998; Near \& Miceli, 1985). Dalam penelitian ini, 
komitmen organisasi yang digunakan adalah komitmen afektif, karena komitmen afektif menunjukan tingkat loyalitas yang lebih baik dibandingkan dengan continuence commitment (komitmen berkelanjutan) dan normative commitment (komitmen normatif). Komitmen afektif merupakan pilihan bebas yang berasal dari keinginan individu itu sendiri, individu bersikap loyal dan setia, karena mereka memang ingin bersikap loyal dan setia (Farrukh et al., 2017; Evanschitzky et al., 2006). Maka dari itu, komitmen afektif digunakan karena memiliki pendekatan yang paling umum pada komitmen organisasi (Allen \& Meyer, 1990).

Motivasi penelitian ini adalah untuk menguji peran komitmen afektif sebagai variabel mediasi antara personality traits dan whistleblowing. Penelitian ini menyempurnakan penelitian sebelumnya karena saat seseorang mengetahui adanya tindakan ilegal, individu dengan karakter tertentu mungkin saja memiliki sikap positif terhadap whistleblowing, sehingga whistleblowing dianggap sebagai tindakan yang benar dan harus dilakukan. Namun saat berhadapan langsung dengan situasi yang sebenarnya, mungkin saja yang dilakukan adalah sebaliknya, individu tersebut tidak melakukan whistleblowing karena takut, tidak peduli, atau merasa tidak ingin merugikan perusahaan (Park \& Blenkinsopp, 2009). Peneliti berasumsi salah satu penyebab lemahnya kecenderungan melakukan tindakan whistleblowing tersebut adalah komitmen yang tinggi pada organisasi. Besar kemungkinan, tindakan whistleblowing tidak dilakukan karena individu merasa memiliki keterikatan yang kuat terhadap organisasi, ingin berkontribusi mencapai tujuan perusahaan, dan tidak ingin merugikan perusahaan, meskipun individu tersebut memiliki karakter yang menunjukan sikap mendukung whistleblowing.

\section{KAJIAN LITERATUR DAN PENGEMBANGAN HIPOTESIS}

\section{Big Five Personality Traits}

Penelitian sebelumnya setuju bahwa meskipun dua individu menjalani peran yang sama, mereka mungkin saja memiliki perilaku yang berbeda (Bateman \& Crant, 1993), perbedaan perilaku tersebut diasumsikan karena adanya perbedaan karakter masingmasing individu yang dibahas dalam personality traits. Personality traits dapat didefinisikan sebagai perbedaan kecenderungan individu dalam menunjukan pola pikir, perasaan, dan tindakan (McCrae \& Costa, 1990). Dole \& Schroeder (2001) berpendapat bahwa personality traits adalah perbedaan karakteristik emosional, kognitif, dan motivasi yang mempengaruhi cara individu untuk membuat keputusan dan menanggapi lingkungannya. Setelah dilakukan banyak penelitian dan analisis faktor selama beberapa dekade, konsep personality traits telah berhasil dianalisis dan pandangan mengenai konsep kepribadian telah menyatu pada satu kesimpulan umum yaitu dapat dijelaskan dalam lima dimensi yang disebut dengan Big Five Personality (John \& Srivastava, 1999; Wiggins and Pincus, 1992; Digman, 1990; McRae \& Costa, 1989). Struktur Big Five telah digeneralisasi lintas budaya, bahasa, dan pengukuran sehingga Big Five telah memberikan struktur kepribadian yang paling banyak diterima di zaman kita sekarang (Judge and Ilies, 2002).

Menurut McCrae \& Costa (1986), Big Five Personality terdiri dari extraversion, agreeableness, conscientiousness, neuroticism, dan openness to experience/intellectual. (1) Extraversion. Pengukuran extraversion didasarkan pada ketegasan, spontanitas, energi, kepercayaan diri, sikap ramah, aktif, banyak bicara, berorientasi pada orang, optimis dan penuh kasih sayang (Lin, 2010; Carver \& Smith, 2010). Penelitian lain berpendapat extraversion memiliki kemampuan bersosialisasi, dan merasa 
nyaman saat bersosialisasi dengan banyak orang (Lucas et al., 2000). (2) Agreeableness, menilai kualitas individu dari tingkat kualitas hubungan melalui kerjasama dan kepercayaan (Lin, 2010). Individu dengan sifat agreeableness yang tinggi cenderung memiliki belaskasihan dan sering berkaitan dengan kemampuan pemeliharaan hubungan (Lin, 2010; JensenCampbell \& Graziano, 2001). Individu dengan kepribadian agreeableness mampu mencegah munculnya perasaan negatif dan tidak mudah marah atas pelanggaran yang dilakukan orang lain (Carver \& Smith, 2010; Meier \& Robinson, 2004), mereka cenderung berhati lembut, baik hati, mudah percaya, gemar membantu, mudah mengampuni, mudah tertipu, dan lugas (Lin, 2010; John \& Srivastava, 1999). (3) Conscientious, menilai kepribadian seseorang dari ketekunan, motivasi, dan perilaku yang mengarah pada pencapaian tujuan. Tingkat conscientious yang tinggi berarti individu cenderung terorganisir, dapat diandalkan, dan pekerja keras (Lin, 2010). (4) Neuroticism, kepribadian seseorang dinilai dari tingkat kerentanan terhadap tekanan psikologis dan pemikiran yang tidak realistis (Lin, 2010). Neuroticism berhubungan dengan mudahnya seseorang menjadi marah dan tertekan, Individu dengan tingkat neuroticism yang tinggi cenderung mudah khawatir, gugup, emosional, depresi, dan peka terhadap ancaman (Carver \& Smith, 2010). (5) Openness to experience, adalah kepribadian individu dinilai dari sikap proaktif dalam mencari dan menghargai pengalaman untuk diri sendiri (Lin, 2010). Individu dengan tingkat openness yang tinggi cenderung kreatif, ingin tahu, imajinatif, berwawasan luas (Lin, 2010), dan memiliki kemauan untuk terlibat dalam pengalaman baru (McCrae, 1996).

\section{Komitmen Afektif}

Komitmen organisasi secara umum didefinisikan sebagai hubungan psikologis antara individu dan organisasi yang dapat memperkecil kemungkinan seseorang untuk meninggalkan organisasi (Allen dan Meyer,
1996), atau kemampuan individu untuk terlibat dalam suatu organisasi tertentu (Porter et al., 1974). Ciri-ciri individu dengan komitmen organisasi memiliki: (1) keyakinan yang kuat dan dapat menerima tujuan serta nilai-nilai organisasi; (2) kemauan untuk memberikan usaha yang cukup demi organisasi; (3) keinginan untuk mempertahankan keanggotaannya dalam organisasi (Mowday et al., 1979).

Menurut Meyer \& Allen (1991), terdapat 3 model komitmen organisasi. Pertama, affective commitment (komitmen afektif) berhubungan dengan keterikatan emosional dan keterlibatan individu dalam organisasi, semakin kuat komitmen afektif seseorang, maka semakin besar keterikatan emosional dan keterlibatannya di perusahaan, sehingga individu dengan komitmen afektif yang tinggi akan terus bekerja di organisasi karena mereka memang ingin melakukannya (Allen \& Meyer, 1991). Kedua, continuance commitment (komitmen berkelanjutan) berhubungan dengan kesadaran individu akan biaya dan manfaat jika meninggalkan/tetap berada di organisasi, individu dengan komitmen berkelanjutan akan tetap bekerja di perusahaan jika keuntungan yang diterima lebih besar daripada kerugian, mereka tetap bekerja di organisasi karena mereka perlu melakukannya (Allen \& Meyer, 1991). Ketiga, individu dengan normative commitment (komitmen normatif) yang tinggi merasa mereka memang seharusnya tetap bekerja di organisasi, hal ini biasanya disebabkan karena adanya penghargaan atau insentif yang diberikan perusahaan pada seseorang sebelum ia bekerja di organisasi, sehingga individu merasa berkewajiban untuk bekerja sampai utang pada perusahaan telah lunas, contohnya seperti beasiswa selama kuliah (Allen \& Meyer, 1991). Komitmen afektif dinilai sebagai komitmen yang paling menunjukan komitmen organisasi karena dilakukan berdasarkan keinginan diri sendiri tanpa ada alasan dan memikirkan untung atau rugi (Evanschitzky et al., 2006). 


\section{Whistleblowing}

Whistleblowing dinilai sebagai perilaku proaktif. Ciri-ciri individu dengan perilaku proaktif adalah berinisiatif untuk melakukan tugas tanpa diminta, memiliki ketegasan, mampu menyelesaikan masalahnya sendiri, mampu bertanggung jawab dalam melaporkan suatu kejadian atau masalah, serta mampu mengambil alih tanggung jawab secara umum (Bjørkelo et al., 2010). Perilaku proaktif berhubungan dengan bagaimana seseorang melalui niat dan tindakan dapat mengubah situasi yang ada (Bateman \& Crant, 1993). Sikap proaktif mencangkup hal-hal seperti mengambil alih tanggung jawab (Moon et al., 2008), melanggar kebijakan formal organisasi (Morrison, 2006), dan berkomunikasi/'voice' (LePine \& Van Dyne, 1998) sebagai tindakan yang dilakukan seseorang untuk menghasilkan perubahan terhadap diri mereka sendiri dan / atau lingkungan. Saat akan mengubah situasi, individu yang pro-aktif mau dan mampu keluar dari batas pekerjaan mereka untuk mengatasi masalah (Morrison, 2006).

Dari sudut pandang perilaku proaktif, secara spesifik whistleblowing dikaitkan dengan sikap proaktif 'suara'/komunikasi yang bertujuan memperbaiki situasi (Bjørkelo et al., 2010). Menurut LePine \& Van Dyne (1998), Istilah 'suara' berhubungan dengan upaya individu untuk berubah, daripada menghindar dari suatu masalah. Terdapat dua jenis 'suara' yaitu promotif (tindakan yang diambil untuk mendorong suatu perubahan terjadi) dan terlarang (tindakan yang mendorong agar suatu kegiatan berhenti). Whistleblowing termasuk dalam 'suara' terlarang karena sifatnya kritis, bertujuan untuk mengakhiri kesalahan yang dikhawatirkan dapat meningkatkan isu-isu mengenai organisasi. Namun penelitian lain berpendapat bahwa whistleblowing juga bersifat promotif, karena whistleblower dapat memberi peringatan pada pemimpin organisasi mengenai adanya suatu potensi bahaya (Miceli \& Near, 1994).
Dari sudut pandang organisasi, whistleblowing adalah perilaku saat individu bertindak berdasarkan rasa moral untuk mengakhiri tindakan ilegal, meskipun menghadapi risiko pembalasan dari anggota organisasi lainnya (Bjørkelo et al., 2010). Menurut Bouville (2008), whistleblowing adalah tindakan yang dilakukan individu untuk melaporkan tindakan ilegal / tidak etis kepada pihak manajemen yang lebih tinggi atau pihak otoritas publik atau otoritas eskternal organisasi. Dalam literatur terdahulu, whistleblowing didefinisikan sebagai pengungkapan oleh anggota organisasi (anggota sebelumnya maupun anggota yang saat ini masih bekerja) mengenai praktik ilegal di bawah kendali perusahaan, kepada pihak yang mungkin dapat melakukan tindakan (Liu \& Ren, 2017; Izraeli \& Jaffe, 1998; Arnold \& Ponemon, 1991; Near \& Miceli, 1985; Latane \& Darley, 1970). Menurut Dozier \& Miceli (1985), whistleblowing adalah perilaku pro-sosial yang dapat menguntungkan masyarakat meskipun risiko utamanya adalah kepentingan dan perlindungan diri sendiri. Hal ini disebabkan karena tidak semua orang memandang whistle blower sebagai pihak yang setia, loyal dan menguntungkan perusahaan, sebagian orang memandang whistle blower sebagai pihak yang mengancam dan mengkhianati norma atau loyalitas organisasi (Rothschild dan Miethe, 1999). Hal ini menunjukan bahwa tindakan whistleblowing adalah keputusan yang sebenarnya beresiko dan begitu sulit untuk dilakukan.

\section{Pengembangan Hipotesis}

\section{Extraversion dan Komitmen Afektif}

Komitmen afektif mengacu pada keterikatan emosional antara individu dengan organisasi, yang ditandai dengan adanya komitmen yang kuat, memiliki keinginan terlibat dan menikmati masa keanggotaan di organisasi (Allen \& Meyer, 1990). Individu dengan tingkat komitmen afektif yang tinggi cenderung bertahan di organisasi karena 
memang mereka menginginkannya. Ciri indivdiu yang memiliki komitmen afektif antara lain memiliki rasa mengabdi dan rasa memiliki (Allen \& Meyer, 1996).

Individu dengan sikap extraversion yang tinggi cenderung ramah, suka berteman, tegas (Lin, 2010; Carver \& Smith, 2010; Barrick \& Mount, 1991). Dalam penelitian terdahulu, extraversion dihubungkan dengan emosi dan disebut sebagai "an emotion-based traits dimension" atau sebuah dimesi sifat berbasis emosi (Watson et al., 1988) yang dapat mempengaruhi individu dalam bersikap dan mengambil keputusan, sehingga dapat menciptakan bias kognitif, seperti persepsi yang menyimpang, pandangan dan persepsi yang tidak logis (Naquin and Holton, 2002). Ada dua jenis emosi, yaitu emosi positif dan negatif. Individu dengan emosi positif cenderung mengalami keadaan emosional yang positif, individu dengan emosi negatif cenderung mengalami keadaan emosional yang negatif (Naquin dan Holton, 2002). Menurut Choi et al., (2015), extraversion cenderung mengalami keadaan emosional yang positif, mereka menggunakan emosi positif untuk mengekspresikan diri, dengan demikian individu extravert cenderung melihat lingkungan kerja mereka dengan lebih positif. Beberapa penelitian telah membuktikan secara empiris hubungan positif antara extraversion dan komitmen afektif (Choi et al., 2015; Syed et al., 2015; Erdheim et al., 2006; Thoresen et al., 2003). Hal ini menujukkan bahwa individu dengan kepribadian extraversion yang tinggi akan memiliki komitmen afektif yang tinggi pada perusahaan karena memiliki keadaan emosional yang positif. Dengan demikian, dapat dihipotesiskan bahwa:

H1: Terdapat hubungan positif antara extraversion dan komitmen afektif

\section{Neuroticism dan Komitmen Afektif}

Individu dengan sifat neuroticism cenderung khawatir berlebihan, emosional, mudah depresi, dan peka terhadap ancaman (Lin, 2010; Carver \& Smith, 2010), hal ini dapat menyebabkan hilangnya pengendalian diri dan pengendalian emosi yang dibutuhkan untuk tetap fokus dan termotivasi dalam bekerja. Individu neuroticism cenderung pesimis dan kurang percaya diri, hal ini juga dapat menyebabkan individu tidak memiliki tujuan karir dan motivasi yang rendah dalam bekerja. Emosi yang tidak stabil dan rendahnya motivasi bekerja menyebabkan kecil kemungkinan individu neuroticism untuk mengabdikan diri pada perusahaan. (Judge and Ilies, 2002; Bozionelos, 2004).

Penelitian terdahulu telah membuktikan secara empiris hubungan negatif antara neuroticism dan komitmen afektif (Gelade et al., 2006). Maka dapat diasumsikan bahwa individu dengan sifat neuroticism memiliki emosi yang tidak stabil, sehingga dapat mempengaruhi motivasi dan sikapnya dalam bekerja, serta memiliki komitmen afektif yang rendah.

H2: Terdapat hubungan negatif antara neuroticism dan komitmen afektif

\section{Komitmen Afektif dan Whistleblowing}

Komitmen afektif diasumsikan menjadi salah satu faktor yang mempengaruh tindakan whistleblowing. Individu dengan komitmen afektif memiliki sikap yang loyal, setia, dan mengabdi pada perusahaan (Farrukh et al., 2017; Evanschitzky et al., 2006). Penelitian sebelumnya menemukan bahwa individu dengan komitmen organisasi yang tinggi memiliki keinginan untuk melakukan whistleblowing, namun hanya keinginan secara internal (Near \& Miceli, 1985). Penelitian tersebut juga diperluas oleh Yustina \& Cintya (2019) pada tindakan whistleblowing, bahwa komitmen afektif berpengaruh negatif terhadap tindakan whistleblowing secara eksternal. Dengan demikian peneliti berasumsi bahwa individu dengan komitmen afektif yang tinggi cenderung tidak melakukan whistleblowing karena individu yang memiliki komitmen afektif yang tinggi memiliki rasa keterikatan yang kuat dan berusaha sebaik mungkin untuk mencapai tujuan organisasi. 
H3: Komitmen afektif berhubungan negatif dengan whistleblowing

Extraversion, Neuroticism, Komitmen Afektif dan Whistleblowing

Komitmen afektif dapat mempengaruhi hubungan antara personality traits dan whistleblowing. Meskipun individu memiliki kepribadian yang cenderung melakukan whistleblowing, namun dengan adanya komitmen afektif yang tinggi, whistleblowing belum tentu akan dilakukan, karena merasa tidak ingin merugikan perusahaan dan merusak reputasi perusahaan.

Dimensi pertama extraversion. Dengan sifatnya yang cenderung percaya diri, ramah, aktif, banyak bicara dan optimis (Lin, 2010; Carver \& Smith, 2010), individu extraversion dapat lebih nyaman dan terampil dalam mengkomunikasikan sesuatu (LePine \& Van Dyne, 2001). Extraversion juga memiliki sifat yang ambisius, ulet, tegas, dan memiliki standar perilaku yang tinggi bagi diri sendiri dalam pekerjaan (Watson \& Clark, 1997) sehingga beberapa penelitian berpendapat bahwa extraversion memiliki hubungan positif dengan whistleblowing. Namun, extraversion merupakan dimensi sifat berbasis emosi (Watson et al., 1988) dan memiliki hubungan positif yang kuat dengan komitmen afektif (Choi et al., 2015; Syed et al., 2015; Erdheim et al., 2006). Hal ini dapat membuat individu mudah dipengaruhi dan memiliki persepsi yang salah, sehingga mereka akan enggan untuk melakukan whistleblowing karena tingginya komitmen afektif dapat membuat mereka terikat secara emosional pada perusahaan dan merasa tidak ingin merugikan perusahaan.

H4a: Komitmen afektif memediasi extraversion dengan whistleblowing.

Berbeda dengan neuroticism yang cenderung mengembangkan sikap negatif terhadap pekerjaan (Bozionelos, 2004) dan memiliki hubungan yang negatif dengan komitmen afektif, hal ini diasumsikan baik karena dengan rendahnya komitmen afektif dan keterikatan emosional dengan perusahaan, individu tidak akan merasa terikat dan merugikan perusahaan (Park \& Blenkinsopp, 2009). Sehingga dengan komitmen afektif yang rendah, individu neuroticism akan merasa lebih leluasa melakukan whistleblowing. Maka dari itu diasumsikan:

H4b: Komitmen afektif memediasi neuroticism dengan whistleblowing.

\section{METODE PENELITIAN \\ Sampel dan Pengumpulan Data}

Untuk menguji hipotesis, kami menggunakan kuesioner berbasis web melalui docs.google.com untuk pengumpulan data. Responden penelitian ini adalah orang - orang yang bekerja di lingkungan akuntan dari perusahaan di Indonesia, seperti auditor, pemilik usaha, karyawan bagian akuntansi, keuangan, pembelian, kasir, dan pajak. Responden dipilih karena peneliti menyadari seringnya orang yang bekerja di lingkungan akuntan menghadapi dilema etika saat bekerja dan betapa pentingnya pelaporan yang dilakukan karyawan ketika mereka menemukan adanya tindakan ilegal di suatu pekerjaan.

\section{HASIL DAN PEMBAHASAN Statistik Desktiptif}

Responden penelitian ini adalah orangorang yang bekerja di lingkungan akuntan dari perusahaan di Indonesia, seperti auditor, pemilik usaha, karyawan bagian akuntansi, keuangan, pembelian, kasir, dan pajak. Responden dipilih karena peneliti menyadari seringnya orang yang bekerja di lingkungan akuntan menghadapi dilema etika saat bekerja dan betapa pentingnya pelaporan yang dilakukan karyawan ketika mereka menemukan adanya tindakan ilegal di suatu pekerjaan. Dari 365 kuesioner yang didistribusikan melalui web, 229 yang kembali dan hanya 95 yang diisi dengan benar dan 
konsisten, tingkat respon yang diisi dengan benar $26.02 \%$. Secara detail, data demografik responden ditunjukkan pada table 1 di bawah ini:

Tabel 1. Demografi Responden

\begin{tabular}{lr}
\hline & $\%$ \\
\hline Jenis Kelamin & \\
$\quad$ Pria & 51,58 \\
Wanita & 48,42 \\
Usia & \\
18 - 25 & 62,10 \\
26 - 33 & 28,42 \\
>33 & 9,48 \\
Jenis Industri & \\
Jasa & 40,00 \\
Perdagangan & 21,05 \\
Manufaktur & 38,95 \\
Posisi Jabatan & \\
Supervisor & 14,74 \\
Manager & 10,53 \\
Staff & 71,58 \\
Junior Auditor & 1,05 \\
Internal Control & 1,05 \\
Owner & 1,05 \\
Divisi Pekerjaan & \\
FAT (Finance, Accounting, Tax) & 83,16 \\
Auditor & 8,42 \\
Kasir & 5,27 \\
Costing & 1,05 \\
Payroll & 1,05 \\
Purchasing & 1,05 \\
Masa Bekerja & \\
<1 tahun & 23,16 \\
3-5 tahun & 42,10 \\
$>5$ tahun & 12,64 \\
\hline Sumber: & 22,10 \\
\hline
\end{tabular}

Sumber: olah data 2019

\section{Pengukuran}

Big Five Personality Traits

Personality trait menggunakan pengukuran yang dikembangkan oleh Donnellan et al., 2006, la mengembangkan pengukuran 20 item kuesioner Mini
International Personality Item Pool dalam penelitiannya untuk mengukur Big Five Personality Traits dengan menggunakan empat item per Big Five traits, Mini IPIP menggunakan lima poin skala Likert, di mana 1 = sangat tidak setuju dan 5 = sangat setuju. Sampel item dalam item extraversion 'I am the life of the party' atau 'Saya sering menjadi pusat perhatian'.

\section{Komitmen Afektif}

Delapan item kuesioner dari Allen \& Meyer (1990) digunakan dalam penelitian ini untuk mengukur komitmen afektif dengan menggunakan lima item skala Likert, di mana 1 = sangat tidak setuju dan 5 = sangat setuju. Sampel item dari skala ini adalah "I really feel as if this organization's problems are my own" atau "Saya merasa bahwa masalah organisasi adalah masalah saya sendiri".

\section{Whistleblowing}

Dalam mengukur whistleblowing, penelitian ini menggunakan pernyataan financial statement fraud yang dikembangkan oleh Crawford \& Weirich (2011), menggunakan lima poin skala Likert, 1 = sangat tidak setuju dan 5 = sangat setuju, dengan sampel pernyataan "I Finding out revenue from sales is recognized without invoice" atau "Saya menemukan pendapatan dari penjualan yang diakui tanpa faktur".

\section{Analisis Statistik}

Dalam penelitian ini aplikasi Warp PLS (3.0) dan SEM-PLS digunakan untuk menguji hubungan antar variabel laten, karena: 1) SEM dapat menguji hipotesis yang dikembangkan berdasarkan teori dan konsep yang sudah ada (analisis multivariat konfirmatoris), 2) SEM memungkinkan untuk menguji hubungan antar variabel laten yang kompleks secara simultan/serempak, sehingga peneliti dapat menganalisis model secara serempak apakah model penelitian terdukung oleh teori dan data. Berbeda dengan analisis dengan regresi berganda yang harus menggunakan beberapa 
persamaan regresi dan menguji variabel dengan bertahap, dikarenakan analisis regresi terbatas hanya dapat menguji dengan satu variabel dependen saja (Smith \& LangfieldSmith, 2004; Hair et al., 2011), 3) SEM PLS dapat menganalisis model pengukuran variabel laten dengan indikator yang sedikit tanpa menimbulkan masalah identifikasi, dan 4) SEM telah digunakan di berbagai bidang penelitian seperti marketing, akuntansi, psikologi, dan sosiologi.

\section{Hasil}

\section{Tes Validitas dan Reliabilitas}

Tabel 2 menyajikan mean, standar deviasi, korelasi antar variabel, dan Cronbach's alpha setiap variabel (huruf tebal sisi diagonal). Tabel 2 menunjukan hubungan yang positif antara extraversion dan komitmen afektif $(r=$ $0,257, p=<0,01)$, dan komitmen afektif memiliki hubungan yang negatif dengan whistleblowing $(r=-0,237, p=0,06)$, komitmen afektif yang tinggi akan membuat seseorang tidak melakukan whistleblowing. Neuroticism dan komitmen afektif menunjukan hubungan yang negatif $(r=-0,247, p=0,05)$. Dalam penelitian ini cronbach's alpha komitmen afektif 0,826, extraversion 0,623, neuroticism 0,429 , dan whistleblowing sebesar 0,625.

Tabel 2. Mean, Standard Deviation, Correlation of Variables, Cronbach Alpha

\begin{tabular}{lcccccc}
\hline & & & & $\mathbf{N}$ & KA & WB \\
& Mean & SD & E & & & \\
\hline$E$ & 2,89 & 1,1 & $\mathbf{0 , 6 2 3}$ & & & \\
$N$ & 3,14 & 1,27 & & $\mathbf{0 , 4 2 9}$ & & \\
KA & 3,14 & 1,24 & $0,257^{* * *}$ & $-0,247^{* *}$ & $\mathbf{0 , 8 2 6}$ & \\
$W B$ & 2,74 & 1,16 & & & $-0,237^{*}$ & $\mathbf{0 , 6 2 5}$
\end{tabular}

E untuk extraversion; $\mathrm{N}$ untuk Neuroticism; KA untuk $\mathrm{K}$ untuk Komitment afektif, dan WB untuk wistheblowing.

Cronbach's alpha berada di posisi diagonal dan bold

${ }^{* * *}$ sig. di $p<0.01 ;{ }^{* *}$ sig. di $p<0.05 ;{ }^{*}$ sig. di $p<0.10$

\section{Model Pengukuran}

Analisis model pengukuran berguna untuk menganalisis pengukuran yang digunakan dengan menilai reliabilitas dan validitas. Penilaian reliabilitas suatu pengukur penting untuk menunjukan seberapa akurat dan konsisten suatu instrument mengukur suatu konsep (Hartono, 2011). Suatu alat ukur dikatakan reliabel jika memiliki nilai cronbach's alpha dan composite reliability di atas 0,70. Dalam penelitian ini composite reliability seluruh variabel di atas 0,70 , komitmen afektif memiliki cronbach's alpha di atas 0,70, extraversion, neuroticism, dan whistleblowing memiliki cronbach's alpha sedikit di bawah 0,70 .
Validitas menunjukan seberapa tepat suatu alat ukur melakukan fungsinya. Terdapat tiga jenis pengujian validitas yaitu validitas konvergen, validitas diskriminan, dan validitas prediktif. Validitas konvergen didukung dengan konstruk yang memiliki nilai loading masingmasing indikator di atas 0,70 dan $p$-values signifikan <0,05 (Hair et al., 2013). Indikator dengan loading di bawah 0,40 harus langsung dihapus dari konstruk, dan indikator dengan nilai loading 0,40 - 0,70 juga dapat dihapus dengan pertimbangan jika penghapusan indikator tersebut dapat meningkatkan average variance extracted (AVE) dengan nilai batas 0,50 dan composite reliability dengan nilai batas 0,70 (Hair et al., 2013). Indikator 
dengan nilai loading untuk validitas konvergen

terdapat di tabel 3.

Tabel 3. Validitas Konvergen dan Tes Reliabilitas Items

Loading

Extraversion (AVE $=0,570 ; \mathrm{CR}=0,799$ )

E1: Saya sering menjadi pusat perhatian. (I am the life of the party)

E2: Saya banyak bicara (I talk a lot)

E4: Saya banyak bicara dan tidak menarik perhatian. (I don't keep in the

background)

0,740

0,781

Neuroticism (AVE $=0,497 ; \mathrm{CR}=0,747$ )

N1: Saya sering mengalami perubahan suasana hati. (I have frequent mood swings)

N3: Saya mudah marah. (I get upset easily)

N4: Saya sering merasa sedih. (I often feel blue)

0,748

0,722

0,641

Komitmen Afektif (AVE $=0,658 ; C R=0,885$ )

AC4: Saya merasa seperti "bagian dari keluarga" di organisasi saya. (I feel

like 'part of the family' at my organization)

AC5: Saya merasa memiliki "ikatan emosional" dengan organisasi saya. (I

feel 'emotionally attached' to this organization)

AC6: Organisasi ini memiliki banyak makna pribadi bagi saya. (This

organization has a great deal of personal meaning for me)

AC7: Saya merasakan rasa memiliki yang kuat terhadap organisasi saya. (I

feel a strong sense of belonging to my organization) 


\section{Whistleblowing (AVE= 0,572, $\mathrm{CR}=\mathbf{0 , 8 0 0 )}$}

WB2: Saya menemukan penangguhan biaya yang tidak tepat saat melakukan uji pisah batas (pemisahan catatan transaksi periode saat ini dengan periode berikutnya). (Finding out improper deferral of costs when conducting cut-off test)

WB 4: Saya menemukan kelebihan jumlah inventory selama stock opname. (I finding out overstated inventory quantities during stock opname) WB 6: Saya menemukan pengungkapan yang tidak cocok dalam catatan kaki laporan keuangan. (Finding out inadequate disclosure in footnotes or management discussion and analysis / MD\&A)

Validitas diskriminan dapat dievaluasi melalui akar kuadrat AVE (kolom yang diberi tanda kurung) harus lebih tinggi dari kolerasi antar variabel laten pada kolom yang sama (di bagian atas atau bawahnya) (Hair et al., 2013). Dalam hal ini validitas diskriman terpenuhi, hasil uji validitas diskriminan terdapat di tabel 4.

Tabel 4. Validitas Diskriminan

\begin{tabular}{lcccc}
\hline & $\mathbf{E}$ & $\mathbf{N}$ & $\mathbf{K A}$ & $\mathbf{W B}$ \\
\hline$E$ & $\mathbf{( 0 , 7 5 5 )}$ & & & $-0,262^{* * *}$ \\
$N$ & $-0,001^{*}$ & $(\mathbf{0 , 7 0 5 )}$ & & \\
KA & $0,223^{* *}$ & $-0,174^{*}$ & $\mathbf{( 0 , 8 1 1 )}$ & \\
\hline WB & $-0,262^{* * *}$ & $0,282^{*}$ & $-0,172^{*}$ & $\mathbf{( 0 , 7 5 6 )}$ \\
\hline
\end{tabular}

E untuk extraversion; N untuk Neuroticism; KA untuk $K$ untuk Komitment afektif, dan WB untuk wistheblowing.

Cronbach's alpha berada di posisi diagonal dan bold ${ }^{* * *}$ sig. di $p<0.01 ;^{* *}$ sig. di $p<0.05 ;{ }^{*}$ sig. di $p<0.10$ Sumber: SEM PLS

Validitas prediktif dinilai dengan $Q$ squared yang berguna untuk menilai relevansi dari sekumpulan variabel laten prediktor pada variabel laten kriterion. Model dengan validitas prediktif harus memiliki $Q$-squared lebih besar dari nol. Dalam penelitian ini, validitas prediktif terpenuhi karena $Q$-squared komitmen afektif 0,130 dan whistleblowing 0,055 . 


\section{Analisis Model Struktural}

Gambar 1 menyajikan hubungan antar variabel yang digunakan untuk menguji pengaruh extraversion dan neuroticism terhadap whistleblowing melalui komitmen afektif. Hubungan antara extraversion dan komitmen afektif signifikan $(\beta=0.26, p<0.01)$, hubungan neuroticism dan komitmen afektif juga signifikan $(\beta=-0.25, p=0,05)$. Oleh karena itu, $\mathrm{H} 1$ dan $\mathrm{H} 2$ terdukung. Hasil penelitian juga menunjukan hubungan yang signifikan antara komitmen afektif dan whistleblowing $(\beta=-0.24, p=0,06)$, dengan demikian $\mathrm{H} 3$ terdukung.

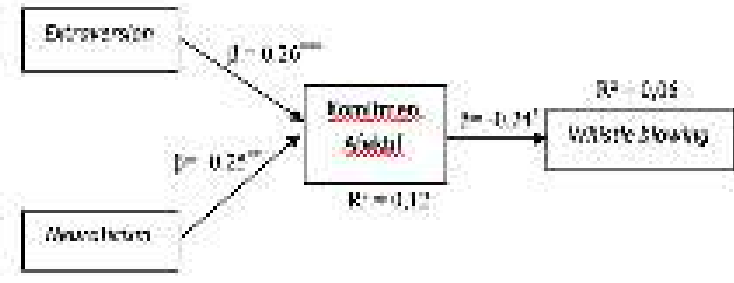

Gambar 1. Model PLS Full

Pada tabel 5 terdapat path Coefficients $\& R$-squared yang akan digunakan untuk menghitung VAF guna mengethui efek variabel komitmen afektif sebagai mediator antara personality traits (extraversion dan neuroticism) dan whistleblowin

Tabel 5. Path Coefficients \& R-squared

\begin{tabular}{|c|c|c|}
\hline \multirow{2}{*}{ Variabel } & \multicolumn{2}{|c|}{ Path Coefficients \& P-Values } \\
\hline & Komiten Afektif & Whistleblowing \\
\hline \multicolumn{3}{|l|}{ Direct } \\
\hline Extraversion & & $-0,315^{* * *}$ \\
\hline $\mathrm{R}^{2}$ & & 0,10 \\
\hline Neuroticism & & $0,324^{* * *}$ \\
\hline $\mathrm{R}^{2}$ & & 0,10 \\
\hline \multicolumn{3}{|l|}{ Mediating } \\
\hline Extraversion & $0,252^{* * *}$ & $-0,298^{* * *}$ \\
\hline Komitmen Afektif & & $-0,214$ \\
\hline $\mathrm{R}^{2}$ & 0,06 & 0,14 \\
\hline Neuroticism & $-0,242^{* *}$ & $0,301^{* * *}$ \\
\hline Komitmen Afektif & & $-0,203$ \\
\hline $\mathrm{R}^{2}$ & 0,06 & 0,15 \\
\hline \multicolumn{3}{|l|}{ Full Model } \\
\hline Extraversion & $0,257^{* * *}$ & \\
\hline Neuroticism & $-0,247^{* *}$ & \\
\hline Komitmen Afektif & & $-0,237^{*}$ \\
\hline Whistleblowing & & \\
\hline $\mathrm{R}^{2}$ & 0,12 & 0,06 \\
\hline
\end{tabular}

Sumber: SEM PLS

Untuk menguji komitmen afektif sebagai variabel pemediasi, peneliti menggunakan tes VAF (Variance Accounted For) yang disajikan di tabel 6, karena uji VAF dinilai lebih tepat untuk SEM-PLS, dan memiliki statistical power yang lebih tinggi dibandingkan metode Sobel (Hair et al., 2013). Jika nilai VAF di atas $80 \%$, maka menunjukan peran variabel mediasi sebagai pemediasi penuh, jika nilai VAF $20 \%$ - $80 \%$ maka dikategorikan sebagai pemediasi parsial, jika kurang dari 20\% dikategorikan tidak ada efek mediasi (Hair et al., 2013). Hasil uji VAF di tabel 6 menunjukkan bahwa nilai VAF komitmen afektif sebagai pemediasi antara extraversion 
terhadap whistleblowing adalah 0,144 (14\%), sedangkan komitmen afektif sebagai variable pemediasi antara neuroticism terhadap whistleblowing adalah 0,131 (13\%). Dapat disimpulkan bahwa tidak ada pengaruh komitmen afektif sebagai pemediasi hubungan antara extraversion dan neuroticism terhadap whistleblowing. Dengan demikian hipotesis $\mathrm{H} 4 \mathrm{a}$ dan $\mathrm{H} 4 \mathrm{~b}$ tidak terdukung.

Tabel 6. Uji VAF

\begin{tabular}{lll}
\hline Indirect Effect (E-KA-WB) & $0,252 *-0,214$ & $-0,053$ \\
Direct Effect (E-WB) & & $\underline{-0,315+}$ \\
Total Effect & & 0,368 \\
\hline VAF for E - KA - WB & & $\mathbf{0 , 1 4 4}$ \\
\hline Indirect Effect (N-KA-WB) & $-0,242 *-0,203$ & 0,049 \\
Direct Effect (N-WB) & & $\underline{0,324+}$ \\
Total Effect & 0,373 \\
\hline VAF for N - KA - WB & $\mathbf{0 , 1 3 1}$ \\
\hline
\end{tabular}

Sumber: SEM PLS

\section{Diskusi}

Peneliti menyelidiki pengaruh dua dimensi personality traits, yaitu extraversion dan neuroticism, kedua dimensi tersebut memiliki pengaruh yang berbeda terhadap mediator. Hubungan yang positif antara extraversion dan komitmen afektif $(\beta=0.26$, $p<0.01)$ menunjukan bahwa individu dengan kepribadian extraversion memiliki komitmen afektif yang tinggi pada perusahaan. Temuan ini konsisten dengan hasil penelitian Erdheim et al. (2006) dan Farrukh et al. (2017), bahwa extraversion memiliki kolerasi yang positif dengan komitmen afektif, dengan demikian $\mathrm{H} 1$ terdukung. Hubungan yang signifikan negatif ( $\beta$ $=-0.25, p=0,05$ ) ditemukan antara neuroticism dan komitmen afektif menunjukan bahwa individu dengan kepribadian neuroticism yang tinggi memiliki komitmen afektif yang rendah pada perusahaan. Temuan ini konsisten dengan hasil penelitian Gelade et al., 2006 dan Judge et al., 2002, bahwa neuroticism memiliki hubungan yang negatif terhadap komitmen afektif, dengan demikian $\mathrm{H} 2$ terdukung. Hasil penelitian menunjukan bahwa tingginya komitmen afektif memiliki pengaruh negatif terhadap whistleblowing ( $\beta=-0.24, p=0,06)$, yang berarti bahwa tingginya komitmen afektif mempengaruhi individu yang bekerja di lingkungan akuntan untuk tidak melakukan whistleblowing. Hasil tersebut didukung dengan hasil penelitian Alleyne (2016) bahwa individu dengan komitmen organisasi yang tinggi enggan untuk melakukan whistleblowing secara eksternal. Menurut Rothschild \& Miethe (1999), sebagian orang berfikir bahwa whistle blower adalah seorang pengkhianat norma, loyalitas, dan kesetiaan pada organisasi sehingga dapat merugikan perusahaan. Individu yang memiliki komitmen afektif tinggi terhadap perusahaan tidak ingin perusahaan mereka memiliki reputasi buruk, dengan demikian $\mathrm{H} 3$ terdukung.

Penelitian ini menguji komitmen afektif sebagai mediator dari hubungan antara personality traits (extraversion \& neuroticism) dan whistleblowing, hasil penelitian menginformasikan bahwa komitmen afektif tidak mempengaruhi hubungan antara extraversion \& neuroticism terhadap whistleblowing, dengan demikian $\mathrm{H} 4 \mathrm{a}$ dan $\mathrm{H} 4 \mathrm{~b}$ tidak terdukung. Hal ini dapat disebabkan karena individu yang bekerja di lingkungan akuntan menerapkan kode etik dalam bekerja, individu yang mengenyam pendidikan akuntansi sendiri sudah menerima banyak materi kode etik akuntan selama masa sekolah dan kuliah, akuntan dituntut memiliki integritas, obyektivitas, dan bersikap profesional. Hal ini menyebabkan keputusan 
untuk melakukan whistleblowing tidak dipengaruhi oleh tinggi / rendahnya komitmen afektif mereka terhadap perusahaan. Ketika individu menemukan hal yang janggal atau ilegal di perusahaan, mereka akan melakukan whistleblowing karena kode etik akuntan sudah tertanam dalam diri akuntan.

\section{PENUTUP}

Penelitian ini menguji pengaruh komitmen afektif sebagai mediator terhadap hubungan personality traits (extraversion \& neuroticism) dan whistleblowing dengan sampel individu yang bekerja di lingkungan akuntan di Indonesia. Setelah mengumpulkan data dari 95 orang yang bekerja di lingkungan akuntan dan diuji dengan SEM PLS, hasil menunjukan bahwa extraversion memiliki hubungan positif dan neuroticism memiliki hubungan negatif terhadap terhadap komitmen afektif, serta komitmen afektif memiliki hubungan yang negatif terhadap whistleblowing.

Hasil dari penelitian ini juga menunjukkan bahwa komitmen afektif tidak memediasi extraversion \& neuroticism terhadap whistleblowing. Hal ini dapat disebabkan karena adanya kode etik yang diterapkan seseorang dalam bekerja, sehingga keputusan tindakan whistleblowing tidak dipengaruhi oleh tinggi / rendahnya komitmen afektif. Ketika individu menemukan tindakan yang ilegal, mereka akan melakukan whistleblowing karena memahami tindakan ilegal tersebut adalah kesalahan dan tidak seharusnya dilakukan.

Maka dari itu penting untuk selalu mengingatkan individu bahwa tindakan mereka sebagai akuntan profesional di praktik publik dan bisnis, serta pekerja di lingkungan akuntan harus sesuai dengan kode etik yang berlaku, seperti bersikap jujur dalam semua hubungan profesional dan bisnis, tidak membiarkan pihak lain mempengaruhi dan mengganggu pertimbangan profesional dan bisnis, serta menghormati kerahasiaan informasi dengan tidak mengungkapkan informasi tersebut kepada pihak ketiga tanpa ada kewenangan yang jelas (Ikatan Akuntan Indonesia, 2016). Kode etik harus sering diingatkan kembali, agar jika ada seseorang dengan kepribadian yang cenderung tidak melakukan whistleblowing mengetahui adanya tindakan ilegal dalam perusahaan, individu tersebut dapat memiliki pedoman untuk melakukan tindakan yang benar dan melakukan pelaporan pada pihak dalam atau pihak luar yang berwenang.

Beberapa penelitian juga membuktikan bahwa karyawan enggan untuk melakukan whistleblowing karena takut akan terjadi risiko yang tidak diinginkan seperti kehilangan pekerjaan, adanya pembalasan, kedekatan hubungan, dan lainnya (Alleyne, 2016). Perusahaan dapat membuat kebijakan dan prosedur yang mendorong karyawan untuk mengkomunikasikan dengan pihak yang berwenang mengenai persoalan etika tanpa takut akan dihukum. Prosedur penerimaan karyawan dan tes psikotes juga penting untuk mengetahui kepribadian masing - masing individu, hal ini berguna agar perusahaan dapat mengetahui personality traits calon karyawan dan memperkirakan apa yang akan dilakukan karyawan ketika mengetahui adanya tindakan ilegal yang dilakukan rekan kerja atau manajemen tingkat atas. Pimpinan pun dapat lebih mengenal karakter dan komitmen karyawan dalam organisasi, serta memberi dukungan saat karyawan melakukan tindakan whistleblowing. Pimpinan yang mendukung pelaporan perilaku disfungsional demi kebaikan perusahaaan, dapat memberi rasa aman bagi akuntan saat mereka melakukan tindakan whistleblowing.

Penelitian ini memiliki beberapa keterbatasan. Pertama, responden dalam penelitian sedikit dan terlalu spesifik dalam hal pekerjaan (individu yang bekerja di lingkungan akuntan) dan kewarganegaraan (Indonesia) sehingga hasil penelitian tidak dijamin dapat berlaku bagi pekerjan dan kewarganegaraan lain. Penelitian selanjutnya diharapkan dapat memperoleh jumlah responden yang lebih banyak dan beragam dari sisi kewarganegaraan 
dan pekerjaan. Kedua, variabel komitmen organisasi yang digunakan hanya komitmen afektif, dan variabel personality traits yang digunakan hanya extraversion dan neuroticism. Penelitian selanjutnya diharapkan dapat diperluas dengan menggunakan faktor lain dari personality traits (McCrae \& Costa, 1986) dan komitmen organisasi (Meyer \& Allen, 1991). Ketiga, standar nilai Cronbach's Alpha yang baik adalah 0,70 namun dalam penelitian ini Cronbach's Alpha sebagian besar variabel di bawah standar dengan nilai extraversion 0,623 ; neuroticism 0,429; dan whistleblowing 0,625, hal ini dapat disebabkan karena banyaknya responden yang menjawab kuesioner dengan tidak konsisten. Keempat, komitmen afektif tidak memediasi personality traits dan whistleblowing. Nilai VAF yang kecil di bawah $20 \%$ juga disebabkan karena adanya hasil yang tidak signifikan dari pengujian mediating effect antara komitmen afektif sebagai mediator extraversion dan whistleblowing $(-0,214)$ serta komitmen afektif sebagai mediator antara neuroticism dengan whistleblowing $(-0,203)$, maka penelitian selanjutnya diharapkan dapat meneliti faktor-faktor lain yang mungkin dapat memediasi personality traits dan whistleblowing, seperti retaliation/pembalasan (Liyanarachchi \& Adler, 2011).

\section{REFERENSI}

Allen, N.J. \& Meyer, J.P. (1990). The measurement and antecedents of affective, continuance and normative commitment to the organization. Journal of Occupational Psychology, 63(1), 1-18.

Allen, N.J. \& Meyer, J.P. (1991). A threecomponent conceptualization of organizational commitment. Human Resource Management Review, 1(1), 6189.

Allen, N.J., \& Meyer, J.P. (1996). Affective, continuance, and normative commitment to the organization: An examination of construct validity.
Journal of Vocational Behavior, 49(3), 252 - 276.

Alleyne, P. (2016). The influence of organisational commitment and corporate ethical values on non-public accountants' whistle-blowing intentions in Barbados. Journal of Applied Accounting Research, 17(2), 190-210.

Arnold, D. \& Ponemon, L. (1991). Internal auditors' perceptions of whistleblowing and the influence of moral reasoning: an experiment. Auditing: A Journal of Practice and Theory, 10(2), 1-15.

Barrick, M.R. \& Mount, M.K. (1991). The big five personality dimensions and job performance: A meta-analysis. Personnel Psychology, 44(1), 1-26.

Bateman, T.S., \& Crant, J.M. (1993). The proactive component of organizational behavior: A measure and correlates. Journal of Organizational Behavior, 14, 103-118.

Bjørkelo, B., Einarsen, S., \& Matthiesen, S.B. (2010). Predicting proactive behaviour at work: Exploring the role of personality as an antecedent of whistleblowing behaviour. Journal of Occupational and Organizational Psychology, 83, 371-394.

Bouville, M. (2008). Whistle-Blowing and Morality. Journal of Business Ethics, 81(3), 579-585.

Bozionelos, N. (2004). The Big Five of personality and work involvement. Journal of Managerial Psychology, 19(1), 69-81.

Carver, C.S., \& Smith, J.C. (2010). Personality and coping. Annual Review of Psychology, 61(1), 679-704.

Choi, D.,Oh,I.-S. \& Colbert, A.E. (2015). Understanding organizational commitment: A meta-analytic examination of the roles of the fivefactor model of personality and culture. Journal of Applied Psychology, 100(5), 1542-1567. 
Cintya, L. \& Yustina, A.I. (2019). From Intention to Action in Whistleblowing: Examining Ethical Leadership and Affective Commitment of Accountants in Indonesia. International Journal of Business, 24(4), 412-433.

Costa. P. T., Jr., \& McCrae. R. R. (1990). Personality disorders and the five-factor model of personality. Journal of Personality Disorders, 6(4), 362-371.

Crawford, R.L., \& Weirich, T.R. (2011). Fraud guidance for corporate counsel reviewing financial statements and reports. Journal of Financial Crime, 18(4), $347-360$.

Digman, J.M. (1990). Personality structure: Emergence of the five-factor model. Annual Review of Psychology, 41(1), 417440.

Dole, C., \& Schroeder, R.G. (2001). The impact of various factors on the personality, job satisfaction and turnover intentions of professional accountants. Managerial Auditing Journal, 16(4), 234 - 245.

Donnellan, M.B., Oswald, F.L., Baird, B.M., \& Lucas, R.E. (2006). The mini-IPIP scales: Tiny-yet-effective measures of the big five factors of personality. Psychological Assessment, 18(2), 192-203.

Dozier, J.B. \& Miceli, M.P. (1985). Potential predictors of whistle-blowing: A prosocial behavior perspective. The Academy of Management Review, 10(4), 823-836.

Dworkin, T.M. \& Baucus, M.S. (1998). Internal vs. External Whistleblowers: A Comparison of Whistleblowing Processes. Journal of Business Ethics, 17(12), 1281-1298.

Erdheim, J., Wang, M., \& Zickar, M.J. (2006). Linking the Big Five personality constructs to organizational commitment. Personality and Individual Differences, 41(5), 959-970.

Evanschitzky, H., Plassmann, H., Iyer, G.R., \& Niessing, J. (2006). The relative strength of affective commitment in securing loyalty in service relationships. Journal of Business Research, 59(12), 1207-1213.

Farrukh, M., Ying, C. \& Mansori, S. (2017). Organizational commitment: An empirical analysis of personality traits. Journal of Work-Applied Management, 9(1), 18-34.

Gelade, G.A., Dobson, P., \& Gilbert, P. (2006). National differences in organizational commitment: Effect of economy, product of personality, or consequence of culture?. Journal of Cross-Cultural Psychology, 37(5), 542-556.

Golberg, L.R. (1993). The structure of phenotypic personality traits. American Psychologist, 48(1), 26-34.

Guenole, N., \& Chernyshenko, O. (2005). The suitability of Golberg's big five IPIP personality makers in New Zealand: A dimensionality, bias, and criterion validity evaluation. New Zealand Journal of Psychology. 34(2), 86-96.

Hair, J., T.Hult, C. Ringle., \& M. Sartstedt. (2013). A Primer on Partial Least Squares Structural Equation Modeling (PLS-SEM). Los Angeles: Sage.

Hartono, J. (2011). Metodologi Penelitian Bisnis (Salah Kaprah dan Pemahaman Pemahaman). Yogyakarta: Fakultas Ekonomika dan Bisnis UGM.

Ikatan Akuntan Indonesia. (2016). Kode etik Akuntan Profesional. Ikatan Akuntan Indonesia (pp. 2-53). Jakarta: Graha Akuntan.

Izraeli, D. \& Jaffe, E.D. (1998). Predicting whistleblowing: A theory of reasoned action approach. International Journal of Value-Based Management, 11(1), 19-34.

Jensen-Campbell, L., \& Graziano, W. (2001). Agreeableness as a moderator of interpersonal conflict. Journal of Personality, 69(2), 323-362.

John, O.P. \& Srivastava,S. (1999). The big five trait taxonomy: History, measurement, and theoretical perspectives. Handbook of Personality: Theory and Research, 102-138. 
Judge, T.A., Heller, D., \& Mount, M.K. (2002). Five-factor model of personality and job satisfaction: A meta-analysis. Journal of Applied Psychology, 87(3), 530-541.

Judge, T.A., \& Ilies, R. (2002). Relationship of personality to performance motivation: A meta-analytic review. Journal of Applied Psychology, 87(4), 797-807.

Latane, B.\& Darley, J.M. (1970). Group inhibition of bystander intervention in emergencies. Journal of Personality and Social Psychology, 10(3), 215-221.

LePine, J.A. \& Dyne, L.V. (1998). Predicting voice behavior in work groups. Journal of Applied Psychology, 83(6), 853-868.

LePine, J.A. \& Dyne, L.V. (2001). Voice and cooperative behavior as contrasting forms of contextual performance: Evidence of differential relationships with big five personality characteristics and cognitive ability. Journal of Applied Psychology, 86(2), 326-336.

Lin, L.Y. (2010). The relationship of consumer personality trait, brand personality and brand loyalty: an empirical study of toys and video games buyers. Journal of Product \& Brand Management, 4-17.

Liu, G., \& Ren, H. (2017). Ethical team leadership and trainee auditors' likelihood of reporting client's irregularities. Journal of Financial Crime, 24(1), 157 - 175.

Liyanarachchi, G. A., \& Adler, R. (2011). Accountants' whistle-blowing intentions: The impact of retaliation, age, and gender. Australian Accounting Review, 167-182.

Lucas, R.E., Diener, Ed., Grob, A., Suh, E.M., \& Shao, L. (2000). Cross-Cultural Evidence for the Fundamental Features of Extraversion. Journal of Personality and Social Psychology, 79(3), 452-468.

McCrae, R, \& Costa, P, T, Jr. (1989). More reasons to adopt the five-factor model. American Psychologist, 44, 451-452.
McCrae, R.R. \& Costa, P.T. Jr. (1996). Toward a new generation of personality theories: Theoretical contexts for the five-factor model. In the five-factor model of personality: Theoretical perspectives. Hrsg.: JS Wiggins. New York. 51-87.

McCrae, R.R., Costa, P.T. Jr \& Busch, C.M. (1986). Evaluating comprehensiveness in personality systems: The California Q-set and the five-factor model. Journal of Personality, 54(2), 430-446.

Meier, B.P., \& Robinson, M.D. (2004). Does quick to blame mean quick to anger? The role of agreeableness in dissociating blame and anger. Personality and Social Psychology Bulletin, 30(7), 856-867.

Miceli, M. P., \& Near, J. P. (1994). Reaping the Benefits. Academy of Management Executive, 8(3), 65-72.

Moon, H., Mayer, D.M., Kamdar, D., \& Takeuchi, R. (2008). Me or we? The role of personality and justice as othercentered antecedents to innovative citizenship behaviors within organizations. Journal of Applied Psychology, 93(1), 84-94.

Morrison, E.W. (2006). Doing the job well: An investigation of pro-social rule breaking. Journal of Management, 32(1), 5-28.

Mowday, R.T., Steers, R.M., \& Porter, L.W. (1979). The measurement of organizational commitment. Journal of Vocational Behavior, 224-247.

Naquin, S.S., \& Holton, E.F. (2002). The effects of personality, affectivity, and work commitment on motivation to improve work through learning. Human Resource Development Quarterly, 13(4), 357-376.

Near, J.P., \& Miceli, M.P. (1985). Organizational dissidence: The case of whistle-blowing. Journal of Business Ethics, 1(1), 1-16.

Park, H., \& Blenkinsopp, J. (2009). Whistleblowing as planned behavior - a survey of south korean police officers. Journal of Business Ethics, 545-556. 
Porter, L.W., Steers, R.M., Mowday, R.T., \& Boulian, P.V. (1974). Organizational commitment, job satisfaction, and turnover among psychiatric technicians. Journal of Applied Psychology, 59(5), 603-609.

Rothschild, J., \& Miethe, T.D. (1999). Whistleblower disclosures and management retaliation: the battle to control information about organization corruption. Work and Occupations. 26(1), 107-128.

Rusting, C.L., \& Larsen, R.J. (1997). Extraversion, neuroticism, and suspectibility to positive and negative affect: A test of two theoretical models. Personality and Individual Differences, 22(5), 607-612.

Syed, N., Saeed, A., \& Farrukh, M. (2015). Organization commitment and five factor model of personality: Theory recapitulation. Journal of Asian Business Strategy, 5(8), 183-190.

Thoresen, C. J., Kaplan, S. A., Barsky, A. P., Warren, C. R., \& de Chermont, K. (2003). The affective underpinnings of job perceptions and attitudes: A metaanalytic review and integration. Psychological Bulletin, 914-945.

Watson, D.\& Clark, L.A. (1988). Development and validation of brief measures of positive and negative affect: The PANAS scales. Journal of Personality and Social Psychology, 54(6), 1063-1070.

Watson, D., \& Clark, L.A. (1997). Extraversion and its possitive emotional core. Handbook of Personality Psychology, 767-793.

Wiggins, J. \& Pincus, A. (1992). Personality: Structure and assessment. Annual Review of Psychology, 43, 473-504. 